\title{
Your Patients with Multiple Sclerosis have Set Wellness as a High Priority- And the National Multiple Sclerosis Society is Responding
}

\author{
Maura Dunn, MS, ${ }^{1}$ Pavan Bhargava, $\mathrm{MD}^{2}$ and Rosalind Kalb, $\mathrm{PhD}^{3}$ \\ 1. Senior Manager, Social Media/Community, National Multiple Sclerosis Society, US; 2. Neuroimmunology Fellow, Department of Neurology, \\ Johns Hopkins University School of Medicine, Baltimore, MD, US; 3. vice President, Healthcare Information and Resources,
}

National Multiple Sclerosis Society, uS

\begin{abstract}
Over the past few years, the National Multiple Sclerosis Society (Society) has been analyzing topics of importance to the MS community across a variety of communication channels. The data show a trend toward decreased trust in pharmacologic approaches and increased interest in more holistic approaches to MS treatment. People living with MS want to know what they can do today-particularly related to diet, exercise, and emotional wellness - to feel and function at their best. In addition, they want the support of knowledgeable healthcare professionals who are armed with accurate information about wellness interventions. This article reports the findings and conclusions from a recent meeting convened by the Society, during which clinicians, researchers, people with MS, and Society staff reviewed what is currently known about diet, exercise, and emotional issues in MS; identified key questions to be answered in each of these domains, along with the research gaps and challenges to be addressed to arrive at the answers; made specific programmatic recommendations to ensure that people living with MS are getting the personalized support and information they need to achieve wellness; and determined next steps to move this important priority forward, some of which are already underway.
\end{abstract}

\section{Keywords}

Multiple sclerosis, National Multiple Sclerosis Society, wellness, exercise, diet, emotion, depression, intervention, research, programs

Disclosure: Pavan Bhargava, MD, receives funding from the National Multiple Sclerosis Society through a Sylvia Lawry Physician Fellowship Award. Maura Dunn, MS, and Rosalind Kalb, PhD, have no conflicts of interest to declare. No funding was received for the publication of this article.

Acknowledgments: The authors wish to acknowledge Wellness Meeting steering committee members, Barbara Appelbaum, ACC, MBA, MAT, Barbara Giesser, MD, and Patricia Kennedy, RN, CNP, MSCN, and the work of Dawn Ehde, PhD, Robert Motl, PhD, and Ellen Mowry, MD, who provided literature review and moderated discussions around gaps, challenges, and opportunities in the areas of mood, exercise, and diet for this meeting.

open Access: This article is published under the Creative Commons Attribution Noncommercial License, which permits any noncommercial use, distribution, adaptation, and reproduction provided the original author(s) and source are given appropriate credit.

Received: July 15, 2015 Published Online: September 17, 2015 Citation: US Neurology, 2015;11(2):80-6 DOI: http://doi.org/10.17925/USN.2015.11.02.80

Correspondence: Rosalind Kalb, PhD, 290 Sabino Road, West Bath, ME 04530, US. E: Rosalind.Kalb@nmss.org

Achieving wellness is a high priority for people living with multiple sclerosis (MS). They want to know what they can do today to feel their best, and whether lifestyle interventions can impact the course of the disease. People with MS are also among the most informed, engaged, and self-advocating patients with chronic illness-proactively seeking information through a variety of channels. ${ }^{1}$

The National MS Society (Society) has observed trends and emerging topics within the MS community for the past few years. One strategy for evaluating interest in certain topics is by analyzing trends in "conversations" over time. We track topics in traditional media, social media, website traffic, and calls to our Information Resource Center (IRC) on a regular basis. We then mine the data collected to find consistencies and inconsistencies (over time, among channels, between specific populations, etc.), explore the meaning behind trends, and determine the Society's response.

\section{Trends and Topics in the Multiple Sclerosis Community} Social Listening

Social listening, which is primarily utilized as a marketing and public relations tool, is the process of identifying and assessing what is being said about a topic, company, individual, or brand on the Internet. Billions of conversations occurring daily-on blogs, message boards, forums, social networks, wikis, microblogs, video sites, online news sources, and more-produce massive amounts of unstructured data. Listening and analytics platforms use keywords to provide structure to the unstructured social data through the use of "smart algorithms." Essentially, the software transposes specific words or phrases in unstructured data into numerical values that are linked to structured data in a database. The structured data can then be analyzed with traditional data-mining techniques. 
Social listening provides an opportunity to tap into day-to-day conversations among people with MS in real time, on a global scalesomething that is not possible in traditional medical and research settings.

\section{Website Traffic}

The Society's website, nationalMSsociety.org, is an online resource for people living with and affected by MS and healthcare professionals. The site is updated regularly based on research, best practices, and visitor feedback. With more than 16,000 pages of content, the site averages approximately 450,000 monthly visitors, $80 \%$ of whom have MS or have a loved one with MS. Recent usability tests revealed that treating MS, understanding or managing symptoms, and fulfilling financial needs are the top priorities for website visitors.

\section{Call Center Interactions}

The Society's IRC is made up of a team of human services professionals providing intake and assessment as well as information and referral services to people living with MS. The goal for of the IRC is to help each person affected by MS to get timely, accurate information and counsel to manage the disease and maintain and enhance independence and quality of life. In 2014, the IRC received approximately 171,000 calls and 11,500 emails. The most frequent requests include resources for emotional support and wellness, referrals to healthcare professionals with knowledge and experience in MS, and solutions to address the financial impact of MS.

\section{Insights We Have Gained}

In spite of dips and spikes over the past few years, interest in wellness strategies for MS symptom management has remained consistently high.

Our preliminary data, including correlations between frequency of symptom- and wellness-related keyword usage, suggest that people with MS are looking to wellness-focused approaches to managing symptoms of MS (see Figure 1). They are trying to solve difficult problems for which we have inconsistent solutions.

Over the past few years, we have seen a trend toward decreased trust in pharmacologic approaches and increased interest in more holistic approaches to MS treatment.

When opinion leaders_-such as celebrities and key MS bloggers-begin showing interest in a topic, including wellness strategies, it tends to get more traditional and social media attention.

More often than not we are told that there is simply no evidence for the effectiveness of this or that alternative therapy, and that rather than waste our time and energy on unproven and possibly dangerous unconventional remedies, we should stick to the triedand-true, which almost always come in the form of pharmaceutical products. (Marc Stecker, Wheelchair Kamikaze [MS blogger]).

We have learned from other high-profile topics, such as chronic cerebral venous insufficiency (CCSVI), stem cell treatments, and cannabis, that when patients feel that their healthcare providers and the Society have not adequately addressed their questions, they are more likely to turn to anecdotal information-potentially putting themselves at risk.

\section{Figure 1: Frequency of Multiple Sclerosis- related Keywords Used in Social Media}

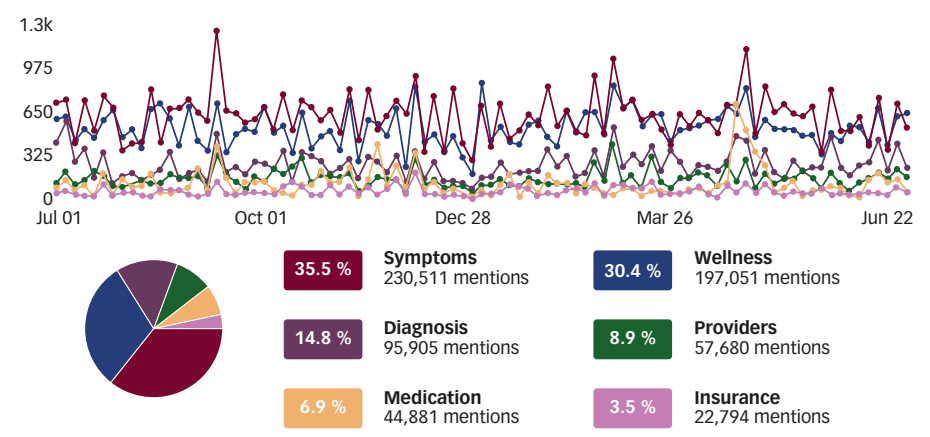

Figure 2: Alternative versus Traditional Treatment Topics Mentioned in Social Media (July 2014-June 2015)

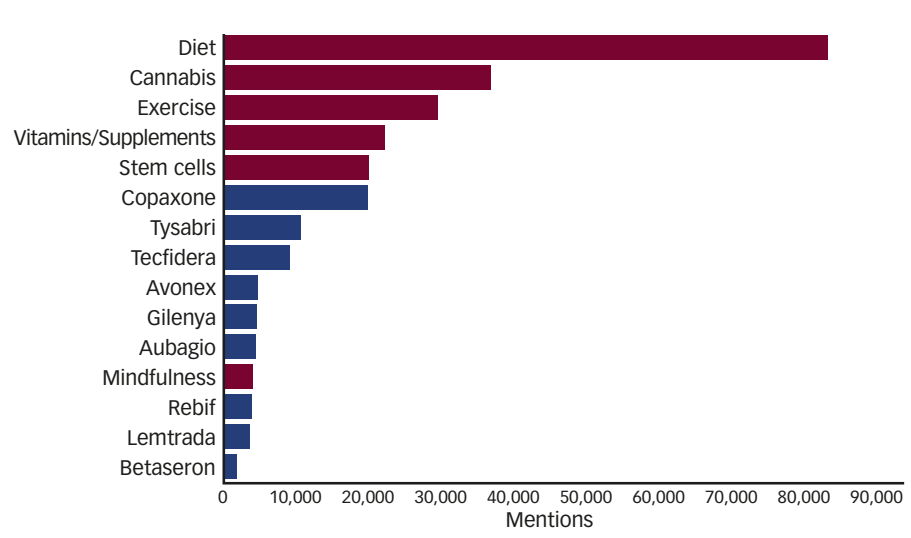

People are seeking understanding. They are looking for researchers and clinicians to engage with them, but they are also looking for their voices to be heard. They want to have an opportunity to weigh in. When we show that we are listening and responding to people's hopes and concerns, we all build credibility and trust.

Three areas of wellness are of special interest to people with MS. They want to know how they can manage their MS with diet and with exercise (see Figure 2). From our strategic planning outreach activities and our targeted daily listening around symptoms, we also know that people with MS want to learn how to manage mood changes_-particularly depression-and develop strategies to achieve emotional wellness. It is interesting to note that information about disease-modifying therapies falls relatively low on the priority list, perhaps because they already have many sources of information about MS treatments.

\section{Doctor-Patient Dialogue around Wellness}

Healthcare professionals are also concerned about their patients' wellness, but face significant challenges in providing guidance or intervention: limited time to cover all that needs to be covered in an office visit, lack of robust data to guide recommendations in the areas of diet and exercise, a don't ask/don't tell conundrum in the area of mood disorders, and inadequate mental health resources in many areas of the country for those with significant mood issues. 
The result appears to be a fairly significant disconnect between what healthcare professionals are discussing with their patients and what their patients want to hear. In the current healthcare environment, the primary focus during short neurology visits tends to be on disease-modifying therapies, with the result that little time is available to talk about wellness strategies. However, as people develop their MS-management plan, they want to understand the role of wellness behaviors, such as dietary modifications, exercise, stress management, and mindfulness, as well as the role of conventional medicine, including disease-modifying therapies and symptom-management medications and strategies. They are asking whether both conventional medicine and wellness behaviors are necessary, whether wellness strategies could be used instead of medication(s), how the greatest benefits be gained, and how soon.

\section{Addressing the Communication Gaps}

To address these priorities, the Society convened a group of people with MS, healthcare professionals, researchers, and Society staff in November 2014 to take the following steps:

- Review the current knowledge in the areas of diet, exercise, and emotional wellness.

- Identify gaps in knowledge in these areas to inform the Society's research agenda.

- Suggest educational resources and support programs in these areas to better meet the needs and interests of people living with MS.

This article reflects the experiences, opinions, and consensus recommendations of the individuals who participated in this meeting.

\section{Achieving Wellness}

The effort to achieve wellness is a lifelong, holistic process that occurs across multiple dimensions-physical, emotional, social, intellectual, occupational, and spiritual-each of which exists along a continuum. ${ }^{2}$ A person's pursuit of wellness involves taking action and making lifestyle choices in some or all of these dimensions with the goal of attaining optimal well-being. While the lifelong process is unique for each individual, wellness is attainable for everyone within the context of his or her priorities and abilities - with a starting point being effective communication between the patient and his or her healthcare providers. That being said, other matters beyond the communication gaps addressed in this article have been shown to reduce utilization of health promotional and wellness services among adults with MS, including educational, social, economic, and disease-related factors that also need to be taken into account in our efforts to help people achieve their optimal wellness. ${ }^{3}$

\section{Wellness-What Do We Know? What Questions Remain to Be Answered?}

An online search for information about diet, exercise, and mood in MS yielded nearly 50 million hits. The challenge for both patients and clinicians lies in trying to make sense out of the array of facts, opinions, advertisements, and personal experiences. Even within the scientific literature, the information is inconclusive and sometimes contradictory.

\section{Diet}

The following studies suggest that diet may play an important role in determining the risk for MS and of disease progression:
- Research findings point to obesity as a possible risk factor for developing MS. The incidence of MS appears to be increasing worldwide ${ }^{4}$ at the same time that caloric intake and being overweight or obese are. ${ }^{5}$ In recent studies, obesity and body size at age 18-20 were associated with an increased risk for $\mathrm{MS}^{6}$ as was higher body mass index (BMI) at age 7-13. ${ }^{7}$ (As defined by the World Health Organization, obesity is defined as a body mass index [BMI: weight in kilograms divided by the square of height in meters $-\mathrm{kg} / \mathrm{m}^{2}$ ] equal to or greater than 30.) Obesity is also associated with low-circulating 25-hydroxyvitamin D concentrations, ${ }^{8}$ which, in turn, are related to disease activity in MS. ${ }^{9}$

- Recent evidence points to sodium intake as a potential factor in MS disease activity. Sodium is a primary component of salt. In an observational study, people who consumed a moderate or high amount of sodium had a higher rate of relapses and a greater risk for developing a new lesion on magnetic resonance imaging than people who consumed a low amount of sodium. ${ }^{10}$

- Several studies have suggested a role for low levels of vitamin $\mathrm{D}$ in disease onset ${ }^{11,12}$ and disease progression. ${ }^{13,14}$ Vitamin $D$ supplementation is being evaluated in a randomized, controlled clinical trial to determine whether this apparent relationship is real or coincidental, and whether the potential benefits outweigh any risks for people with MS.

- The potential role of polyunsaturated fatty acids (PUFAs) in slowing disease activity has also been studied, with mixed results. In a Cochrane Review, ${ }^{15}$ PUFAs did not affect disease progression although relapses seemed to be less frequent. As is being performed with vitamin D supplementation, carefully controlled trials are necessary to identify potential benefits and risks.

- The gut microbiota, which is influenced by diet and other factors, modulates the immune system and appears to play a role in MS onset. ${ }^{16,17}$

- Chronic caloric restriction attenuates experimental autoimmune encephalomyelitis ${ }^{18}$ and intermittent feeding attenuates clinical course of experimental autoimmune encephalomyelitis in C57BL/6 mice. ${ }^{19}$ Overall, research studies in the area of diet have generally been of inadequate size and design to provide conclusive information about dietary strategies in MS. For example, in the Cochrane Review on dietary interventions, ${ }^{15}$ only six randomized, controlled trials of PUFAs (with a total of 794 patients) met the inclusion criteria for the review. The evidence available thus far related to dietary factors is insufficient to establish either efficacy (how well a particular diet or supplement works in the structured environment of a controlled clinical trial) or effectiveness (how consistently or persistently people can use a diet or supplement in everyday life).

The following questions need to be answered about diet in MS:

1. What is the impact of a given dietary strategy on the underlying disease process in MS? On symptoms?

2. Are different dietary strategies effective for different individuals, or does one type of diet fit all people with MS?

3. Is it possible for people to change their eating habits over the long term?

4. How can researchers identify those dietary interventions that might hold promise for people with MS?

5. Do dietary interventions change the way MS medications are absorbed and used by the body? 


\section{Exercise}

A substantial body of research demonstrates that exercise is good for a person's overall health and for reducing comorbidities, including obesity, cardiovascular disease, some cancers, type 2 diabetes, osteoporosis, and mood disorders. ${ }^{20}$ In people with MS, exercise has been shown to be effective for improving aerobic capacity ${ }^{21-23}$ and muscle strength, ${ }^{24,25}$ mobility, ${ }^{26,27}$ quality of life, ${ }^{28}$ and symptoms of fatigue. ${ }^{29}$ Exercise may also be effective in treating depression, although the evidence is conflicting. ${ }^{30-33}$ In spite of all the purported benefits of exercise for people with MS, the efficacy or effectiveness of any specific exercise program for people with MS has not been established. ${ }^{34}$

Of note, the amount of sedentary behavior among people with MS is alarmingly high, regardless of their physical abilities or limitations ${ }^{35}$; yet we know very little about strategies that help people become more physically active. Klaren et al. ${ }^{36}$ report data from a pilot trial suggesting that a behavioral intervention can reduce sitting time in people with MS, but conclude that more research is needed to determine the impact of reduced sitting on function, symptoms, quality of life, and health status.

The following questions need to be answered about exercise in MS:

1. Is exercise training a disease-modifying and/or symptomatic therapy? Does exercise influence the underlying disease process in MS?

2. What is the effect of exercise on symptoms, including cognition, sleep, and pain? Does exercise help manage more severe symptoms as well as milder symptoms?

3. What is the optimal amount (intensity and frequency) of exercise for people with MS? Does the optimal amount vary by severity of the disease?

4. How do we encourage and support the initiation and maintenance of exercise behaviors in people with MS? What is the role of healthcare professionals in encouraging people with MS to exercise?

5. What are the causes of sedentary behavior among people with MS? Can increasing a person's overall activity level produce benefits similar to those seen with a regular exercise program?

6. How do individuals with MS differ (in terms of disease course, disease severity, symptoms) in the kinds of exercise that would be most beneficial?

\section{Emotional Wellness}

From the time of diagnosis, people with MS use a variety of selfmanagement strategies to maintain or enhance their emotional wellbeing in the face of MS-related challenges. However, due to a variety of factors (small study sizes; inadequate design of clinical trials; and a lack of consistency in the groups studied and in the way anxiety, depression, or stress is defined and measured), research has not determined the efficacy or effectiveness of most of these interventions. Thus far, research suggests that:

- Exercise (aerobic and, perhaps, resistance training) may help reduce depressive symptoms and being physically active may help people feel less depressed over time; 30,31

- Telephone-delivered physical activity counseling (including motivational strategies, goal-setting, and action planning) may reduce the severity of depression in people who become more active; ${ }_{3}^{37}$
- Acupuncture, Feldenkrais, guided imagery, hypnotherapy, massage, meditation, mindfulness, music therapy, prayer and spirituality, Tai chi, and yoga may be effective in reducing mild to moderate depressive symptoms, anxiety, and stress; ${ }^{38}$

- St John's wort may be effective for treating mild to moderate depression in some individuals; ${ }^{39}$

- Adaptive and solution-focused coping help to promote adaptation and adjustment in MS; ${ }^{40,41}$ and

- Stress-management strategies of various types may help to reduce stress and improve mood and quality of life.38,42,43

People with MS who experience more severe mood disturbances, including major depression, may be unable to engage actively or effectively in any wellness strategies, including emotional wellness strategies, physical exercise, or healthy eating practices. For these individuals, identifying and treating the mood disturbances is necessary before they can embrace lifestyle changes that may lead to wellness.

The following questions need to be answered about emotional well-being in people with MS:

1. Can we demonstrate in controlled clinical trials the impact of wellness behaviors, such as guided imagery, prayer and spirituality, and massage, on feelings of depression, anxiety, and stress?

2. Can we identify a "menu" of effective strategies (including medication, psychotherapy, and wellness behaviors) that could be tailored to the emotional needs of each individual at different points in time?

3. How do we attract, train, and retain mental health professionals in MS care?

4. How can we ensure that people at risk for significant mood disturbances are identified at different points in the disease course?

5. Who, in addition to mental health professionals, can safely and effectively treat mild to moderate mood issues?

\section{Wellness Research-Challenges to Addressing Gaps in Our Knowledge}

The review of the published research about diet, exercise, and emotional wellness highlighted the importance of determining the relative efficacy and effectiveness (see "Addressing the communication Gaps") of wellness strategies_alone or in combination_for managing symptoms, reducing other (comorbid) health conditions, and enhancing the impact of diseasemodifying therapies on MS disease activity.

Several challenges must be overcome to address these gaps in knowledge and establish a successful research agenda:

- How to identify and prioritize the target groups to study, for example: - Individuals with relapsing disease or those with progressive disease.

- Individuals who are newly diagnosed, for studies designed to prevent symptoms or progression, or those with more progressed MS for studies designed to intervene and provide disease modification or symptom relief.

- How to determine the appropriate control group for each study to demonstrate most clearly the impact of the intervention being studied, for example: 
Table 1: Diets for Multiple Sclerosis at a Glance

\begin{tabular}{|c|c|c|c|c|c|}
\hline Diet & Basic Guidelines & Restrictions & Possible Deficiencies & $\begin{array}{l}\text { Evidence for Benefit in } \\
\text { Multiple Sclerosis }\end{array}$ & $\begin{array}{l}\text { Evidence for Benefit in } \\
\text { Other Diseases }\end{array}$ \\
\hline Paleolithic diet ${ }^{44}$ & $\begin{array}{l}\text { Emphasizes consumption of game } \\
\text { meats ( } 30-35 \% \text { of daily caloric intake) } \\
\text { and plant foods (besides cereals), } \\
\text { multiple daily servings of green, and } \\
\text { sulfur-rich and intensely colored } \\
\text { vegetables and fruits, with a high intake } \\
\text { of PUFAs to target a ratio of saturated } \\
\text { to unsaturated fats of 1.4:2.1 }\end{array}$ & $\begin{array}{l}\text { Processed food, } \\
\text { domesticated meats, } \\
\text { dairy, eggs }\end{array}$ & $\begin{array}{l}\text { Folic acid, thiamine, } \\
\text { vitamin } B 6 \text {, calcium and } \\
\text { vitamin } D \text {, insufficient } \\
\text { caloric intake }\end{array}$ & $\begin{array}{l}\text { Single-observation study } \\
\text { demonstrating possible } \\
\text { improvement in fatigue in } \\
\text { progressive MS patients } \\
\text { (however diet was bundled } \\
\text { with other interventions } \\
\text { and there was no } \\
\text { comparison group) }\end{array}$ & $\begin{array}{l}\text { Single study showed } \\
\text { improvement in } \\
\text { cardiovascular risk factors }^{45}\end{array}$ \\
\hline $\begin{array}{l}\text { Mediterranean } \\
\text { diet }^{46}\end{array}$ & $\begin{array}{l}\text { High intake of whole grains, } \\
\text { vegetables, fruits, legumes, olive oil, } \\
\text { and fish; a low intake of saturated } \\
\text { fats (butter and other animal fats), } \\
\text { red meat, poultry, and dairy products; } \\
\text { and a regular but moderate intake of } \\
\text { ethanol (mainly red wine) }\end{array}$ & No specific exclusions & None expected & None & $\begin{array}{l}\text { Extensive evidence for a } \\
\text { benefit on cardiovascular } \\
\text { health, diabetes, and } \\
\text { possibly on cancer risk } \\
46-49\end{array}$ \\
\hline McDougall diet50 & $\begin{array}{l}\text { High-carbohydrate, low-fat, low- } \\
\text { sodium vegan diet with cereals, } \\
\text { potatoes, and legumes as staples. } \\
\text { Fruits and vegetables are allowed } \\
\text { in any amount. Low-sodium intake } \\
\text { and small amounts of sugar are } \\
\text { recommended }\end{array}$ & $\begin{array}{l}\text { Dairy, eggs, meat, } \\
\text { poultry, fish, and all oils }\end{array}$ & $\begin{array}{l}\text { Iron, vitamin B12, } \\
\text { vitamin D, calcium, } \\
\text { and } \omega 3 \text {-fatty acids }\end{array}$ & None & $\begin{array}{l}\text { One study showed } \\
\text { improvement in } \\
\text { cardiovascular risk factors } \\
\text { with } 1 \text { week of the diet } \\
\text { (did not look at long-term } \\
\text { effects) })^{50}\end{array}$ \\
\hline Gluten-free diet ${ }^{51}$ & $\begin{array}{l}\text { Avoidance of all foods containing } \\
\text { wheat, barley, and triticales or their } \\
\text { derivatives }\end{array}$ & $\begin{array}{l}\text { Foods containing wheat, } \\
\text { barley, or triticales or } \\
\text { their derivatives }\end{array}$ & None expected & None ${ }^{52,53}$ & $\begin{array}{l}\text { Treatment for celiac } \\
\text { disease and non-celiac } \\
\text { gluten sensitivity }\end{array}$ \\
\hline Swank diet ${ }^{54}$ & $\begin{array}{l}\text { Low-fat diet that advocates reduction in } \\
\text { the intake of saturated fats. Whole-grain } \\
\text { cereals are recommended; daily intake } \\
\text { of two servings of fruits and vegetables } \\
\text { and intake of white fish and shellfish } \\
\text { and trimmed poultry is allowed. Low- } \\
\text { fat dairy is allowed and small quantities } \\
\text { of red meat are permissible after the } \\
\text { first year of the diet }\end{array}$ & $\begin{array}{l}\text { Processed food with } \\
\text { saturated fats, high-fat } \\
\text { dairy products, and red } \\
\text { meat for the first year }\end{array}$ & $\begin{array}{l}\text { None expected } \\
\text { (possibly vitamin } \\
\text { A, C, E, and folate) }\end{array}$ & $\begin{array}{l}\text { Observational data from a } \\
\text { single cohort of patients } \\
\text { treated with this diet } \\
\text { suggested an improvement } \\
\text { in relapses and functional } \\
\text { status (there was no control } \\
\text { comparison group) }{ }^{54}\end{array}$ & None \\
\hline
\end{tabular}

- A group on the waiting list for the intervention.

- A group receiving a sham intervention (placebo) or a different treatment intervention (known as an "active control").

- A group receiving standard care.

- How to address the challenges in adhering to a wellness intervention (e.g., a diet, exercise regimen, or mindfulness protocol) over long periods of time.

- How to address the ways in which significant mood changes and/or MS-related cognitive changes may influence a person's ability to engage in wellness activities, such as exercising and eating a healthy diet.

- How to find and train knowledgeable scientific reviewers to assess wellness research proposals that are somewhat different from proposals submitted for basic science (laboratory) research.

- How to address concerns some in the medical community may have that wellness research is not a high priority.

- How to expand resources to fund large-scale, well-designed, and controlled multisite studies in wellness.

\section{Wellness Research Recommendations}

After careful consideration of the identified research gaps and challenges, the following recommendations were made:

1. Engage research design experts to address the challenges identified within and across wellness areas.

2. Stimulate collaborative research efforts, similar to what has been carried in the areas of genetics, nervous system repair, and progressive MS, to ensure that the best minds are working with speed and effectiveness in wellness research.

3. Identify funding partners who share our interest in increasing knowledge about wellness interventions in MS.

\section{In the Meantime-Recommendations for Clinician-Patient Interactions}

In each of the targeted wellness areas-diet, exercise, and emotional health-strategies were identified to expand education and resources for people with MS and healthcare providers to promote physical and emotional well-being. 


\section{Diet}

- Provide clear recommendations to people with MS based on what is known today about the role of diet in overall health:

- Limit sugar and processed foods (particularly those high in sugar, salt, and sodium).

- Increase fruits and vegetables.

- Choose lean sources of protein.

- Choose healthy fats.

- consume adequate fiber and fluids.

- Provide unbiased information about popular "MS diets" to support educated decision-making (see Table 1).

- Focus on reducing obesity since it appears to increase the risk for MS, and also increases the risk for other health conditions that can worsen a person's MS.

- Consider creating dietary guidelines for people with MS.

\section{Exercise}

- Provide clear recommendations based on what we know today about the impact of exercise on overall health, MS symptoms (including mobility, weakness, balance, cognition, mood, and pain), and quality of life.

- Educate healthcare professionals about the role of exercise in health and MS management, and encourage them to talk to their patients about "exercise as medicine."

- Partner with community organizations (e.g., the YMCA) to provide exercise programs for people with MS.

\section{Emotional Wellness}

- Develop strategies and tools to increase doctor-patient conversations about emotional wellness beginning at the time of diagnosis, such as:

- Toolkit of information tips and tools for people with MS to identify mood changes in themselves and talk about those changes with their healthcare provider(s); and

- Information and tools for healthcare professionals to talk about mood changes with their patients and to facilitate referrals to the society and mental health professionals in the community.

- Identify proactive strategies to promote emotional well-being and prevent significant mood disruption in people newly diagnosed with MS.

- Increase the numbers of individuals (peers with MS, Society MS Navigators, mental health professionals) who can deliver effective interventions (prevention, diagnosis, treatment, support) from the time of diagnosis onward.

\section{The Society's Response}

Based on the recommendations from this meeting, the society has convened a work group in June 2015 to address the following concerns about depression in MS:
- Lack of well-designed studies to identify the cause(s) of mood changes and the interventions that might be helpful for each individual.

- High prevalence of severe depression and anxiety among people living with MS.

- Underdiagnosis and undertreatment of depression and other mood changes in people with MS.

- Complex, probably interrelated, causes (immune changes and changes in the brain, as well as psychosocial stressors) of depression in MS.

- Impact of depression on quality of life, ability to take care of oneself, adherence to treatment, and MS symptoms, such as cognition, pain, and fatigue.

- Possible role of depression and stress in central nervous system inflammation and the disease process.

- Insufficient numbers of mental health professionals to provide diagnosis and treatment.

In addition, the Society will:

- Design and implement a strategy to educate healthcare professionals about the role of wellness in MS comprehensive care and the importance of diet, exercise, and emotional wellness;

- Create an MS Wellness Research Network-including researchers in the areas of diet, exercise, and mood, as well as researchers from other disease groups and experts in study design and statistical analysiswith the goal of developing study design criteria and specific research methodologies for wellness-focused research;

- Develop a long-term strategy for funding research in wellness interventions; and

- Evaluate existing programs and explore development of new programs that would inform, encourage, and facilitate participants' pursuit of personal wellness.

\section{Summary}

People living with MS identify wellness as a high priority in their lives. They want to know what they can do today-particularly related to diet, exercise, and emotional wellness - to feel and function at their best. In addition, they want the support of knowledgeable healthcare professionals, who are armed with accurate information about wellness interventions, as they pursue their wellness goals. At a recent meeting convened by the Society, people with MS, healthcare professionals, researchers, and society staff summarized what is currently known about diet, exercise, and emotional issues in MS; identified key questions to be answered in each of these areas, along with the research gaps and challenges to be addressed to arrive at the answers; made specific programmatic recommendations to ensure that people living with MS are getting the personalized support and information they need to achieve wellness; and outlined next steps to move this important priority forward.
1. Marrie RA, Salter AR, Tyry T, et al., Preferred sources of health information in persons with multiple sclerosis: degree of trust and information sought, I Med Internet Res, 2013;15:e67.

2. Miller JW, Wellness: the history and development of a concept, 2005. Available at: http://www.fh-joanneum.at/global/show_ document.asp?id=aaaaaaaaaabdjus\& (accessed on June 6, 2015).

3. Plow M, Cho C, Finlayson M, Utilization of health promotion and wellness services among middle-aged and older adults with multiple sclerosis in the mid-west US, Health Promot Int 2010;25:318-30.

4. Benito-Leon J, Multiple sclerosis: is the prevalence rising and if so why?, Neuroepidemiology, 2011;37:236-7.

5. Centers for Disease Control and Prevention, Overweight and obesity. Available at: http://www.cdc.gov/obesity/data/facts. $\mathrm{html}$ (accessed on June 6, 2015)

6. Munger KL, Chitnis T, Ascherio A, Body size and risk of MS in two cohorts of US women, Neurology, 2009;73:1543-50 7. Munger KL, Bentzen J, Laursen B, et al., Childhood body mass index and multiple sclerosis risk: a long-term cohort study, Mult Scler, 2013;19:1323-9.

8. Earthman CP, Beckman LM, Masodkar K, Sibley SD, The link between obesity and low circulating 25 -hydroxyvitamin D
concentrations: considerations and implications, Int J Obes, 2012;36:387-96. 
9. Ascherio A, Munger KL, White R, et al., Vitamin D as an early predictor of multiple sclerosis activity and progression, JAMA Neurol, 2014;71:306-14.

10. Farez MF, Fiol MP, Gaitán MI, et al., Sodium intake is associated with increased disease activity in multiple sclerosis, J Neurol Neurosurg Psychiat, 2015;86:26-31.

11. Munger KL, Levin LI, Hollis BW, et al., Serum 25 -hydroxyvitamin D levels and risk of multiple sclerosis, JAMA, 2006;296:2832-8.

12. Martinelli V, Dalla Costa G, Colombo B, et al., Vitamin D levels and risk of multiple sclerosis in patients with clinically isolated syndromes, Mult Scler, 2014;20:147-55.

13. Ascherio $A$, Munger $K L$, White $R$, et al., Vitamin $D$ as an early predictor of MS disease activity and progression, JAMA Neurol, 2014;71:306-14.

14. Mandia D, Ferraro OE, Nosari G, et al., Environmental factors and multiple sclerosis: a descriptive study, Int J Environ Res Pub Health, 2014;11:6417-32

15. Farinotti $M$, Vacchi $L$, Simi S, et al., Dietary interventions for multiple sclerosis, Cochrane Database Syst Rev, 2012 Dec 12;12:CD004192, doi: 10.1002/14651858.CD004192.pub3.

16. Bhargava P, Mowry E, Gut microbiome and multiple sclerosis, Curr Neurol Neurosci Rep, 2014;14:492.

17. Riccio $P$, Rossano $R$, Nutrition facts in multiple sclerosis, ASN Neuro, 2015;18;7(1)

18. Piccio L, Stark JL, Cross AH, Chronic calorie restriction attenuates experimental autoimmune encephalomyelitis, J Leukoc Biol, 2008;84:940-8.

19. Kafami L, Raza M, Razavi A, et al., Intermittent feeding attenuates clinical course of experimental autoimmune encephalomyelitis in C57BL/6 mice, Avicenna J Med Biotechnol, 2010:2:47-52

20. Centers for Disease Control and Prevention, Physical activity. Available at: http://www.cdc.gov/physicalactivity/everyone/ health/index.html (accessed on June 6, 2015).

21. Petajan $\mathrm{JH}$, Gappmaier $\mathrm{E}$, White $\mathrm{AT}$, et al., Impact of aerobic exercise training on fitness and quality of life in multiple sclerosis, Ann Neurol, 1996;39:432-41.

22. Mostert S, Kesselring J, Effects of a short-term exercise training program on aerobic fitness, fatigue, health perception and activity level of subjects with multiple sclerosis, Mult Scler. 2002:8:161-8

23. Rampello A, Franceschini M, Piepoli M, et al., Effect of aerobic training on walking capacity and maximal exercise tolerance in patients with multiple sclerosis: a randomized crossover controlled study, Phys Ther, 2007;87:545-55

24. Dalgas U, Stenager E, Jakobsen J, et al., Resistance training improves muscle strength and functional capacity in multiple sclerosis, Neurology, 2009;73:1478-84.

25. Sá MJ, Exercise therapy and multiple sclerosis: a systematic review, J Neurol, 2014;261:1651-61.

26. Van den Berg M, Dawes $H$, Wade $D$, et al., Treadmill training for individuals with MS: a pilot randomized trial, J Neurol Neurosurg Psychiat, 2006:77:531-3.

27. Motl $R$, Pilutti $L$, The benefits of exercise training in multiple sclerosis, Nat Rev Neurol, 2012;8:487-97.

28. Motl RW, MCAuley E, Snook EM, Gliottoni RC, Physical activity and quality of life in multiple sclerosis: intermediary roles of disability, fatigue, mood, pain, self-efficacy and social support, Psychol Health Med, 2009;14:111-24.

29. Pilutti $L$, Greenlee $T$, Motl $R$, et al., Effects of exercise training on fatigue in multiple sclerosis: a meta-analysis, Psychosom Med, 2013;75:575-80

30. Feinstein A, Rector N, Motl R, Exercising away the blues: can it help multiple sclerosis-related depression?, Mult Scler, 2013;19:1815-9.

31. Ensari I, Motl RW, McAuley E, et al., Patterns and predictors of naturally occurring change in depressive symptoms over a 30-month period in multiple sclerosis, Mult Sclerosis J, 2014;20:602-9.

32. Latimer-Cheung AE, Pilutti LA, Hicks AL, et al., Effects of exercise training on fitness, mobility, fatigue, and health-related quality of life among adults with multiple sclerosis: a systematic review to inform guideline development, Arch Phys Med Rehabil, 2013;94:1800-28.

33. Giesser $\mathrm{BS}$, Exercise in the management of persons with multiple sclerosis, Ther Adv Neurol Disord, 2015;8:123-30.

34. Motl RW, Learmonth YC, Pilutti LA et al., Top 10 research questions related to physical activity and multiple sclerosis, Res Q Exerc Sport, 2015:86:117-29.

35. Ellis T, Motl RW, Physical activity behavior change in persons with neurologic disorders: overview and examples from Parkinson disease and multiple sclerosis, I Neurol Phys Ther 2013;37:85-90.

36. Klaren RE, Hubbard EA, Motl RW, Efficacy of a behavioral intervention for reducing sedentary behavior in persons with multiple sclerosis: a pilot examination, Am J Prev Med, 2014:47:613-6.

37. Bombardier CH, Ehde DM, Gibbons LE, et al., Telephone-based physical activity counseling for major depression in people with multiple sclerosis, J Consult Clin Psychol, 2013;81:89-99.

38. Bowling A, Optimal Health with Multiple Sclerosis, New York: Demos Health, 2014

39. Linde K, Kriston L, Rücker G, et al., Efficacy and acceptability of pharmacological treatments for depressive disorders in primary care: systematic review and network meta-analysis, Ann Fam Med, 2015;13:69-79

40. Linde K, Sigterman K, Kriston L, et al., Effectiveness of psychological treatments for depressive disorders in primary care: systematic review and meta-analysis, Ann Fam Med, 2015:13:56-68.

41. Dennison L, Moss-Morris R, Chalder T, A review of psychological correlates of adjustment in patients with multiple sclerosis, Clin Psychol Rev, 2009;29:141-53.

42. Foley FW, Bedell JR, LaRocca NG, et al., Efficacy of stressinoculation training in coping with multiple sclerosis, J Consult Clin Psychol, 1987;55:919-22.

43. Grossman $P$, Kappos $L$, Gensicke $H$, et al., MS quality of life, depression and fatigue improve after mindfulness training: a randomized trial, Neurology, 2010;75:1141-9.

44. Bisht B, Darling WG, Grossmann RE, et al., A multimodal intervention for patients with secondary-progressive multiple sclerosis: feasibility and effect on fatigue, I Altern complement Med, 2014;20:347-55.

45. Boers I, Muskiet FA, Berkelaar E, et al., Favourable effects of consumimg a Palaeolithic-type diet on characteristics of the metabolic syndrome: a randomized controlled pilot-study, Lipids Health Dis, 2014:13:160.

46. Ostan R, Lanzarini C, Pini E, et al., Inflammaging and cancer: a challenge for the Mediterranean diet, Nutrients, 2015;7:2589-621.

47. Schwingshackl L, Hoffmann G, Adherence to Mediterranean diet and risk of cancer: a systematic review and meta-analysis of observational studies, Int J Cancer, 2014;135:1884-97.

48. Huo R, Du T, Xu Y, et al., Effects of Mediterranean-style diet on glycemic control, weight loss and cardiovascular risk factors among type 2 diabetes individuals: a meta-analysis, Eur $\mathrm{Clin}$ Nutr, 2014 [Epub ahead of print].

49. Schwingshackl L, Hoffmann G, Mediterranean dietary pattern inflammation and endothelial function: a systematic review and meta-analysis of intervention trials, Nutr Metab Cardiovasc Dis, 2014;24:929-39.

50. MCDougall J, Thomas $L E$, McDougall $C$, et al., Effects of 7 days on an ad libitum low-fat vegan diet: the McDougall Program cohort, Nutr I, 2014:13:99.

51. El-Chammas K, Danner E, Gluten-free diet in nonceliac disease, Nutr Clin Pract, 2011:26:294-9.

52. Hadjivassiliou M, Sanders DS, Grünewald RA, Multiple sclerosis and occult gluten sensitivity, Neurology, 2005;64:933-4.

53. Pengiran Tengah CD, Lock RJ, Unsworth DJ, Wills AJ, Multiple sclerosis and occult gluten sensitivity, Neurology, 2004:62:2326-7.

54. Swank RL, Multiple sclerosis: twenty years on a low fat diet, Arch Neurol, 1970:23:460-74. 